\title{
Identifying the design skies for Indian tropical climatic conditions
}

\author{
Nabeel Ahmed Khan*, Paras Malik and Bishwajit Bhattacharjee
}

Indian Institute of Technology Delhi, Delhi 110 016, India

\begin{abstract}
The current Indian design sky model is inadequate for daylighting design and calculation of annual daylight energy savings in buildings due to which designers are compelled to resort to other sky luminance prediction models like Perez and International Commission on Illumination (CIE) sky models. Perez and CIE sky models are derived from the sky scan data of mostly sub-tropical and temperate regions where the climatic conditions are different from the tropical climatic conditions. The present study attempts to check and compare the adequacy of Perez and CIE sky models for prediction of sky luminance in Indian tropical climatic conditions by comparing model-predicted values with the measured values from the past studies. Further, a framework has been proposed for the identification of CIE design skies for passive window design in the locations where measured sky luminance data is not available. CIE design skies have been recommended for the major climatic zones of the tropical climate of India using the proposed framework.
\end{abstract}

Keywords: Design sky, passive window design, daylighting, Indian tropical region.

INDIAN Standard Code IS 2440 (ref. 1) recommends a design sky model for passive window design in India. Accordingly, the sky luminance at an altitude angle of $\theta$ is given as

$$
L_{v}=L_{z} \operatorname{cosec} \theta
$$

where $L_{v}$ is the luminance of the sky element at the altitude angle of $\theta$ and $L_{z}$ is the sky luminance at zenith. The formula is applicable for sky elements lying between $15^{\circ}$ and $90^{\circ}$ sky altitude with uniform brightness below $15^{\circ}$ sky altitude. Uniform luminance is assumed along the azimuthal direction for a given sky altitude angle. The design sky given in the code has been derived based on the measurements taken at CBRI (Central Building Research Institute, Roorkee, India) at $15^{\circ}$ solar altitude in 1975 (refs 1, 2). Basic hypothesis for above design sky is: $15^{\circ}$ altitude represents the time corresponding to that at one hour after sunrise ( 7 a.m. or so) or one hour before sunset (5 p.m. or so), covering complete working hours.

*For correspondence. (e-mail: nabeel.k91@gmail.com)
The daylight availability would be minimum during working hours at that time and represents the lower limit of sky luminance for design purpose. Passive window design with a low solar altitude design sky ensures daylight availability through fenestration throughout the working hours and is, therefore, a reasonable assumption. It was further assumed that fenestration design for daylight would prefer window on north wall to exclude direct sun light so as to avoid glare and heat admission. Thus diffused sky on north-east or north-west quadrant of the sky hemisphere opposite to the sun's position was considered in the morning and afternoon respectively. Hence the assumption of azimuthal uniformity was adopted. But assuming azimuthal uniformity may lead to an inefficient design, which is explained as follows.

According to the measured sky luminance data of other tropical countries and established sky luminance prediction models $s^{3,4}$, the sky luminance varies as the distance from the sun changes (both in azimuth and altitude). A good passive window design requires precise prediction of sky luminance in every direction of the sky dome. Apart from this, Indian design sky does not take into consideration the change in sky conditions with the change in climatic zones. It is also inadequate for calculation of annual energy savings due to daylight as it gives a single sky luminance distribution for a low solar altitude angle and leads to underestimation of the daylight availability. The shortcomings of the current Indian design sky model as described above are azimuthal uniformity, climate invariant and inadequacy for calculation of annual energy savings due to daylight. These shortcomings compel the designers to employ other sky luminance prediction models for window design purposes and annual building energy load calculations. Perez ${ }^{5}$ and International Commission on Illumination (CIE) sky models ${ }^{6}$ are widely accepted models for the prediction of sky luminance distribution. Daylight simulation softwares used by architects like Gendaylit Sky Generator in Radiance $^{7}$, Daysim $^{8}$ and Daylight Visualizer ${ }^{9}$ use Perez and CIE sky models for prediction of sky luminance distribution.

The coefficients used for the prediction of sky luminance in Perez and CIE sky models are derived from the regression analysis of the measured data from countries mostly falling in subtropical and temperate regions. The climatic conditions of tropical regions differ considerably 
from that prevalent in sub-tropical and temperate regions. It is still a matter of question if the sky luminance prediction model derived from the sky scan data of the sub-tropical and temperate climatic region predicts sky luminance correctly for Indian tropical climatic regions as well. In the present study, an attempt has been made to check the adequacy of Perez and CIE sky luminance prediction models for Indian tropical climatic conditions by comparing the model predicted values with the measured values available from past studies. The unavailability of measured luminance data limits the use of the CIE sky model for passive window design in many countries. Therefore, a framework has been developed to propose CIE design skies for passive window design using the irradiance data for the locations where measured luminance data is not available. A set of design skies have been proposed for the major climatic zones of the Indian tropical climate using the proposed framework.

\section{Literature review}

A few authors have attempted to validate the accuracy of Perez and CIE sky models for sky luminance prediction in tropical regions and have also identified suitable standard CIE sky types for countries in the tropical climatic region. Tregenza ${ }^{10}$ measured the sky luminance distribution at the stations in Singapore, Japan, Garston (UK) and Sheffield (UK) and compared it with the modelled sky luminance of the 15 standard skies proposed by $\mathrm{CIE}^{6}$ and Perez sky model ${ }^{5}$ using root mean square error method to check the adequacy of the proposed sky models in representing the actual sky conditions occurring under the climatic condition of these cities. Mukherjee ${ }^{11}$ attempted to identify a suitable sky type for Delhi (India) by comparing the ratio of zenith luminance to horizontal diffuse illuminance for the CIE standard skies with the measured values for Delhi. Diffuse horizontal illuminance was calculated by an empirical model given in the CBRI report. In the study, CIE sky types 8 and 6 (partly cloudy sky) were identified as suitable skies for summer and winter seasons respectively. Mukherjee and Roy ${ }^{12}$ again attempted to find out the suitable sky type for Roorkee in three different seasons through comparison of the spatial illuminance values obtained on a working plane using the CIE standard skies and the measured sky luminance values. The results revealed that CIE clear sky of type 15 (white-blue turbid sky) is suitable for luminance predictions in summer and equinox seasons and CIE clear sky of type 11 (white-blue sky) for the winter season. Li et $a l .{ }^{13}$ measured the sky luminance for Hong Kong sky and compared the sky luminance distribution with modelled sky luminance distribution for the $15 \mathrm{CIE}$ standard skies by the root mean square error method to arrive at a subset of three sky types which were sufficient to describe the sky occurrence in subtropical Hong Kong. Mettanant et $a l .{ }^{14}$ tried to develop a new method to model sky luminance distribution of Thailand using the reduced set from the CIE standard skies and optimized limit values of the Perez's clearness and sky brightness parameters for accurate sky classification. The authors used the stochastic search technique of evolutionary computation for obtaining the optimized limit values.

It can be seen from the literature review that the researchers in the past have attempted to propose methodologies and have identified suitable CIE sky types for some tropical countries, but a similar type of comprehensive study for Indian tropical climate has not been done. Also, there seems to be no readily available study to propose design skies for the passive design of windows for daylighting in the tropical climatic zone. Indian tropical conditions are different from other tropical countries because of modifications due to the massive mountainous range of the Himalayas in the north and oceans in the south. The following section gives an overview of the Indian tropical climate and how it is different from the climate of other countries in the same latitude.

\section{Tropical zones of India}

Most parts of India fall under tropical region as it spans from $8^{\circ}$ lat. in Kanyakumari to $34^{\circ}$ lat. in Leh. There are massive Himalayan mountain ranges in the north and oceans such as the Indian Ocean, Arabian Sea and Bay of Bengal surrounding the southern part of the country. Besides these, other mountainous ranges of lesser altitudes are also present, e.g. the Eastern Ghats, Western Ghats and Nilgiris in the southern peninsula and Satpura, Vindhyachal and Aravali in the central part of the country. The topographical features induce climatic changes that make Indian climatic conditions different from the other countries in the same tropical region. One major difference is the existence of a specific climate zone as a composite monsoon climate which is not prevalent in most of the other tropical locations. Monsoon is triggered from the oceans near tropic of cancer during summer, whereby moisture-bearing winds travel towards the north and cause precipitation when they come in contact with the mountainous range of Himalayas. This phenomenon modifies the climatic condition in the major part of North and Central India. Besides, Northern polar winds get blocked by the same mountainous ranges causing moderation of the winter conditions. However, the countries falling under the same latitude range experience different climatic conditions. For example, the latitude of Arizona and part of Northern India is almost the same $\left(30 \pm 3^{\circ} \mathrm{N}\right)$. However, while part of Arizona is a desert, similar latitude locations in India experience composite climate.

The National Building Code ${ }^{15}$ classifies the country into five climatic zones, namely (1) hot and dry, (2) warm 
Table 1. Classification of climatic zones (adapted from BIS 2005)

\begin{tabular}{lcc}
\hline Climatic zone & $\begin{array}{c}\text { Mean monthly } \\
\text { maximum temperature }\left({ }^{\circ} \mathrm{C}\right)\end{array}$ & $\begin{array}{c}\text { Mean monthly relative } \\
\text { humidity percentage }\end{array}$ \\
\hline Hot and dry & Above 30 & Below 55 \\
Warm and humid & Above 30 & Above 55 \\
Temperate & Above 25 & Above 75 \\
Cold & Between $25-30$ & Below 75 \\
\hline
\end{tabular}

Table 2. Measured luminance data

\begin{tabular}{llcl}
\hline \multicolumn{1}{c}{$\begin{array}{c}\text { Season/ } \\
\text { Place }\end{array}$} & \multicolumn{1}{c}{ date of measurement } & Solar altitude & \multicolumn{1}{c}{ Source } \\
\hline Roorkee & March equinox/21 March & $59.74^{\circ}$ & Mukherjee and Roy $^{2,3}$ \\
Roorkee & Summer solstice/21 June & $82.57^{\circ}$ & Mukherjee and Roy ${ }^{2,3}$ \\
Roorkee & Winter solstice (25 December) & $38.33^{\circ}$ & Mukherjee and Roy ${ }^{2,3}$ \\
Delhi & Winter & $20^{\circ}$ & Sastri and Manmohan $^{4}$ \\
Delhi & Winter & $40^{\circ}$ & Sastri and Manmohan $^{4}$ \\
Mumbai & Winter/11 December 1963 & $30^{\circ}$ & Narsimhan and Saxena $^{5}$ \\
Nagpur & Winter/13 January 1964 & $45^{\circ}$ & Narsimhan and Saxena $^{5}$ \\
\hline
\end{tabular}

and humid, (3) temperate, (4) cold and (5) composite. The criteria for the classification of these climatic zones are the mean monthly maximum temperature and mean monthly percentage relative humidity. Table 1 gives the range of temperature and relative humidity for the classification of these climatic zones. Each zone experiences particular weather conditions for more than six months whereas there may be a change in the weather for a few months. Hot and dry climatic zones experience high maximum temperature, high diurnal ranges and low humidity for most part of the year. Warm and humid zones experience somewhat lower maximum temperatures, lower diurnal ranges with high humidity. Temperate climatic zones experience moderate temperatures with moderate humidity, whereas cold climatic zones have low temperatures during most part of the year. The composite climatic zone does not have any weather conditions continuously for more than six months.

\section{Methodology}

For checking the adequacy of the Perez and CIE sky model in predicting sky luminance distribution under Indian tropical conditions, the model predicted values were checked against measured values taken from past studies for some major cities in India. A summary of the measured sky luminance data from past studies and the Perez and CIE sky model is given in the following sections.

\section{Measured sky luminance data}

Data for four cities such as Roorkee, Delhi, Nagpur and Mumbai in different seasons were taken from the literature. Sky luminance data for Roorkee were measured at
CBRI as a part of the International Daylight Measurement Program ${ }^{12}$. The measurements were taken for the whole sky vault in three minutes using a sky scanner from M/s EKO Japan, having a field view of $11^{\circ}$ at 12:00 noon for the three seasons of the summer solstice, winter solstice and March equinox. The data were recorded at 12 intervals of altitude starting from $6^{\circ}$ above the horizon and every 30 azimuthal intervals for a total of 145 points on the entire sky vault ${ }^{12}$. The measured luminance values were plotted in the form of iso-luminance contours ${ }^{12}$. Sky luminance data for Delhi were measured ${ }^{16}$ using a sky scanning photometer and were plotted in the form of isoluminance contours for $20^{\circ}$ and $40^{\circ}$ solar altitude for the winter months of 1969-70. Luminance data for Mumbai and Nagpur were measured by Narsimhan and Saxena ${ }^{2}$ at solar altitudes of $30^{\circ}$ and $45^{\circ}$ respectively and the data were plotted in the form of iso-luminance contours. The above-mentioned set of measured data for four locations in different seasons were used to check the adequacy of Perez and CIE sky models for sky luminance prediction. Table 2 lists all the measured luminance data along with their source, date/season of measurement, place of measurement and solar altitude at the time of measurement. The luminance values plotted in the form of contour lines were linearly interpolated to get the luminance value between two successive contours lines. Luminance values were divided by the luminance at zenith in the contours to obtain relative luminance values. Table 3 shows the relative luminance values obtained for Roorkee city in all the three seasons.

\section{Sky models}

The CIE sky model is the current standard for sky luminance prediction as adopted by the International 
RESEARCH ARTICLES

Table 3. Measured relative sky luminance values for Roorkee

\begin{tabular}{|c|c|c|c|c|c|c|c|c|c|c|c|c|}
\hline Azimuth & 0 & 30 & 60 & 90 & 120 & 150 & 180 & 210 & 240 & 270 & 300 & 330 \\
\hline \multicolumn{13}{|c|}{ Altitude (Roorkee summer solstice) } \\
\hline 10 & 0.20 & 0.21 & 0.15 & 0.22 & 0.25 & 0.24 & 0.24 & 0.21 & 0.20 & 0.15 & 0.14 & 0.17 \\
\hline 20 & 0.22 & 0.23 & 0.24 & 0.27 & 0.29 & 0.28 & 0.27 & 0.26 & 0.25 & 0.23 & 0.21 & 0.21 \\
\hline 30 & 0.25 & 0.25 & 0.26 & 0.30 & 0.32 & 0.32 & 0.31 & 0.29 & 0.27 & 0.26 & 0.24 & 0.23 \\
\hline 40 & 0.27 & 0.27 & 0.28 & 0.35 & 0.38 & 0.39 & 0.37 & 0.33 & 0.31 & 0.28 & 0.26 & 0.26 \\
\hline 50 & 0.29 & 0.30 & 0.32 & 0.42 & 0.51 & 0.53 & 0.53 & 0.43 & 0.36 & 0.31 & 0.30 & 0.28 \\
\hline 60 & 0.34 & 0.36 & 0.42 & 0.57 & 0.76 & 0.95 & 0.93 & 0.60 & 0.47 & 0.38 & 0.34 & 0.33 \\
\hline 70 & 0.44 & 0.51 & 0.60 & 0.88 & 1.25 & 1.20 & 1.40 & 0.83 & 0.65 & 0.55 & 0.45 & 0.44 \\
\hline 80 & 0.66 & 0.75 & 0.86 & 1.15 & 1.52 & 1.20 & 1.40 & 0.91 & 0.86 & 0.76 & 0.66 & 0.66 \\
\hline 90 & 1.00 & 1.00 & 1.00 & 1.00 & 1.00 & 1.00 & 1.00 & 1.00 & 1.00 & 1.00 & 1.00 & 1.00 \\
\hline \multicolumn{13}{|c|}{ Altitude (Roorkee winter solstice) } \\
\hline 10 & 0.50 & 0.50 & 0.50 & 1.00 & 1.56 & 5.00 & 6.50 & 2.25 & 1.29 & 0.75 & 0.75 & 0.75 \\
\hline 20 & 0.75 & 0.75 & 0.75 & 1.00 & 2.00 & 5.00 & 6.50 & 2.71 & 1.43 & 1.00 & 0.75 & 0.75 \\
\hline 30 & 0.75 & 0.75 & 0.75 & 1.00 & 2.00 & 5.00 & 9.06 & 3.07 & 1.47 & 1.00 & 0.75 & 0.75 \\
\hline 40 & 0.75 & 0.75 & 0.75 & 1.00 & 1.96 & 5.00 & 10.00 & 3.06 & 1.42 & 1.00 & 0.75 & 0.75 \\
\hline 50 & 0.75 & 0.75 & 0.75 & 1.00 & 1.77 & 4.58 & 7.08 & 2.69 & 1.37 & 1.00 & 0.75 & 0.75 \\
\hline 60 & 0.75 & 0.75 & 0.77 & 1.00 & 1.58 & 3.07 & 3.54 & 2.32 & 1.32 & 1.00 & 0.75 & 0.75 \\
\hline 70 & 0.75 & 0.75 & 0.85 & 1.00 & 1.38 & 2.08 & 1.75 & 1.96 & 1.27 & 1.00 & 0.75 & 0.75 \\
\hline 80 & 0.81 & 0.86 & 0.92 & 1.00 & 1.19 & 1.21 & 1.16 & 1.57 & 1.15 & 1.00 & 0.84 & 0.82 \\
\hline 90 & 1.00 & 1.00 & 1.00 & 1.00 & 1.00 & 1.00 & 1.00 & 1.00 & 1.00 & 1.00 & 1.00 & 1.00 \\
\hline \multicolumn{13}{|c|}{ Altitude (Roorkee march equinox) } \\
\hline 10 & 0.50 & 0.50 & 0.40 & 0.67 & 0.86 & 1.24 & 1.35 & 1.00 & 0.83 & 0.54 & 0.52 & 0.50 \\
\hline 20 & 0.50 & 0.50 & 0.52 & 0.70 & 1.03 & 1.46 & 1.58 & 1.13 & 0.84 & 0.67 & 0.55 & 0.50 \\
\hline 30 & 0.50 & 0.50 & 0.55 & 0.74 & 1.12 & 1.76 & 2.20 & 1.28 & 0.89 & 0.67 & 0.57 & 0.50 \\
\hline 40 & 0.50 & 0.50 & 0.58 & 0.78 & 1.21 & 2.78 & 3.13 & 1.50 & 0.94 & 0.67 & 0.60 & 0.50 \\
\hline 50 & 0.50 & 0.51 & 0.62 & 0.83 & 1.36 & 4.38 & 6.11 & 1.67 & 0.99 & 0.72 & 0.62 & 0.50 \\
\hline 60 & 0.50 & 0.58 & 0.65 & 0.87 & 1.50 & 4.70 & 5.83 & 1.67 & 1.00 & 0.79 & 0.65 & 0.55 \\
\hline 70 & 0.61 & 0.65 & 0.73 & 0.91 & 1.67 & 3.67 & 3.54 & 1.67 & 1.00 & 0.86 & 0.71 & 0.64 \\
\hline 80 & 0.78 & 0.81 & 0.87 & 0.96 & 1.33 & 1.50 & 1.56 & 1.33 & 1.00 & 0.93 & 0.83 & 0.78 \\
\hline 90 & 1.00 & 1.00 & 1.00 & 1.00 & 1.00 & 1.00 & 1.00 & 1.00 & 1.00 & 1.00 & 1.00 & 1.00 \\
\hline
\end{tabular}

Commission on illumination ${ }^{17}$. A set of fifteen standard skies were proposed by Darula and Kittler ${ }^{6}$ derived from the sky scan measurement data recorded in Tokyo, Berkeley and Sydney as a part of the International Daylight Measurement program (IDMP) which was later adopted by CIE as a standard. CIE sky model requires the measured value of zenith luminance and horizontal diffuse illuminance for the selection of sky type from the representative set of possible sky luminance distributions. Sky luminance or illuminance is not measured at the Indian Meteorological stations and thus limits the use of the CIE sky model in countries like India. CIE model defines a total of 15 possible sky luminance distributions. The table given in the standard ${ }^{17}$ lists six groups of $k$ and $l$ values for the gradation function and six groups of $m, n$ and $p$ values for the indicatrix function. A total of 15 combinations of these coefficients define the change in relative luminance with the zenith angle and angular distance of the sky element from the sun. For future reference, the table has been reproduced here as Table 4 . The table defines the sky conditions corresponding to each sky type and the corresponding values of the parameters. For the identification of CIE sky type from the set of skies given in the standard, the relative luminance from the measured luminance data was compared against the relative luminance predicted by 15 CIE sky types for each of the cities and seasons. The CIE sky type having the least error for a particular city and season was chosen as the CIE sky type for that city and season. These chosen CIE sky types for different cities were then used to assess the accuracy of the CIE sky model in the comparative study.

Perez sky model was developed based on the sky scan data measured from ten American and three European cities $^{5}$. The model relates the sky luminance distribution to the insolation conditions through coefficients which define the sky conditions for a particular location, day and time of the year. Perez model is more versatile in the sense that the parameters used for luminance prediction are derived from irradiance measurements at the place under consideration, the data for which is easily available at most of the meteorological stations. For the calculation of Perez coefficients, solar radiation data for all the cities except Roorkee were taken from the solar radiation handbook $^{18}$. In this handbook ${ }^{18}$, radiation data is given for the representative year or typical meteorological year of the respective cities which was developed by Sandia National Laboratories, $\mathrm{USA}^{19}$. The typical meteorological year is a dataset in which hourly values of solar radiation 
RESEARCH ARTICLES

Table 4. International Commission on Illumination (CIE) sky types (adapted from Darula and Kittler ${ }^{6}$ )

\begin{tabular}{|c|c|c|c|c|c|c|c|c|}
\hline Type & Gradation & Indicatrix & $k$ & $l$ & $m$ & $n$ & $p$ & Description of luminance distribution \\
\hline 1 & I & 1 & 4 & -0.7 & 0 & -1 & 0 & $\begin{array}{l}\text { CIE Standard Overcast Sky, alternative form steep luminance } \\
\text { gradation towards zenith, azimuthal uniformity }\end{array}$ \\
\hline 2 & I & 2 & 4 & -0.7 & 2 & -1.5 & 0.15 & $\begin{array}{l}\text { Overcast, with steep luminance gradation and slight brightening } \\
\text { towards the sun }\end{array}$ \\
\hline 3 & II & 1 & 1.1 & -0.8 & 0 & -1 & 0 & Overcast, moderately graded with azimuthal uniformity \\
\hline 4 & II & 2 & 1.1 & -0.8 & 2 & -1.5 & 0.15 & Overcast, moderately graded and slight brightening towards the sun \\
\hline 5 & III & 1 & 0 & -1 & 0 & -1 & 0 & Sky of uniform luminance \\
\hline 6 & III & 2 & 0 & -1 & 2 & -1.5 & 0.15 & $\begin{array}{l}\text { Partly cloudy sky, no gradation towards zenith, slight brightening } \\
\text { towards the sun }\end{array}$ \\
\hline 7 & III & 3 & 0 & -1 & 5 & -2.5 & 0.3 & $\begin{array}{l}\text { Partly cloudy sky, no gradation towards zenith, brighter } \\
\text { circumsolar region }\end{array}$ \\
\hline 8 & III & 4 & 0 & -1 & 10 & -3 & 0.45 & Partly cloudy sky, no gradation towards zenith, distinct solar corona \\
\hline 10 & IV & 3 & -1 & -0.55 & 5 & -2.5 & 0.3 & Partly cloudy, with brighter circumsolar region \\
\hline 11 & IV & 4 & -1 & -0.55 & 10 & -3 & 0.45 & White-blue sky with distinct solar corona \\
\hline 12 & $\mathrm{~V}$ & 4 & -1 & -0.32 & 10 & -3 & 0.45 & CIE Standard Clear Sky, low illuminance turbidity \\
\hline 13 & $\mathrm{~V}$ & 5 & -1 & -0.32 & 16 & -3 & 0.3 & CIE Standard Clear Sky, polluted atmosphere \\
\hline 14 & VI & 5 & -1 & -0.15 & 16 & -3 & 0.3 & Cloudless turbid sky with broad solar corona \\
\hline 15 & VI & 6 & -1 & -0.15 & 24 & -2.8 & 0.15 & White-blue turbid sky with broad solar corona \\
\hline
\end{tabular}

Table 5. Parameters and their respective weightage factors used for arriving typical meteorological year in solar radiation handbook (adapted from IMD 2009)

\begin{tabular}{lc}
\hline Parameter & Weightage factor \\
\hline Global solar irradiance & $7 / 23$ \\
Diffuse solar irradiance & $6 / 23$ \\
Mean air temperature & $2 / 23$ \\
Maximum air temperature & $1 / 23$ \\
Minimum air temperature & $1 / 23$ \\
Mean dew point temperature & $2 / 23$ \\
Maximum dew point temperature & 123 \\
Minimum dew point temperature & $1 / 23$ \\
Mean wind speed & $2 / 23$ \\
\hline
\end{tabular}

and meteorological elements are selected in the form of months from individual years and later concatenated to form a complete year. The data collected in this form gives a standard data set that has frequency distribution close to the long term distribution. The sandia method uses nine parameters for selecting a representative month and each parameter is assigned a specific weightage. Table 5 gives the parameters used to arrive at the typical meteorological year in the solar radiation handbook. As can be seen, a large weightage has been assigned to global and diffuse irradiation. The data obtained from the typical meteorological year can be assumed to be representative of the long term solar radiation data for the locations. The data set for Roorkee was obtained by averaging 15 years (2000-2014) of irradiation data obtained from the National solar radiation database ${ }^{20}$ as it was not available in the solar radiation handbook.

\section{Prediction and comparison of sky luminance data}

For checking and comparing the accuracy of the two sky models, the whole sky dome was divided into sky patches at $10^{\circ}$ intervals of altitude starting from $10^{\circ}$ above the horizon to $80^{\circ} \mathrm{sky}$ altitude at every $30^{\circ}$ azimuthal interval resulting in a total of 96 sky patches on the entire sky vault. Relative sky luminance was predicted using the Perez sky model and the chosen CIE sky type of the CIE sky model at the centre of these 96 sky patches. Relative luminance at the centre of the sky patches was also obtained from the iso-luminance contours of the measured data from the past studies as shown in Table 3.

Root mean square error and mean bias error metrics were used to test how well the predicted values matched with the measured values. These metrics were used for their ability to evaluate the nature of differences between predicted values of models against the observed values as recommended by researchers ${ }^{21}$. Mean bias error was used to get an idea about the average bias prediction of the luminance values. The formula used for calculating the root mean square error and mean bias error values is as given below.

Mean bias error

$$
\mathrm{MBE}=\frac{1}{n} \sum_{i=1}^{n} \frac{x_{i}-\bar{x}}{\bar{x}} .
$$

Root mean square error

$$
\mathrm{RMSE}=\sqrt{\frac{1}{n} \sum_{i=1}^{n}\left(\frac{x_{i}-\bar{x}}{\bar{x}}\right)^{2}} .
$$


Table 6. Error metrics for best fit CIE sky and Perez model predicted values for Roorkee city

\begin{tabular}{|c|c|c|c|c|c|c|}
\hline City/season & $\begin{array}{c}\text { CIE } \\
\text { sky type }\end{array}$ & $\begin{array}{c}\text { RMSE } \\
(\%)\end{array}$ & $\begin{array}{c}\mathrm{MBE} \\
(\%)\end{array}$ & $\begin{array}{l}\text { Standard } \\
\text { deviation }\end{array}$ & $\begin{array}{c}\text { Percentage } \\
\text { error }\end{array}$ & $\begin{array}{l}\text { Correlation } \\
\text { coefficient }\end{array}$ \\
\hline \multicolumn{7}{|l|}{ CIE } \\
\hline Roorkee/winter solstice & 11 & 19 & 2.60 & 0.19 & 11.75 & 0.97 \\
\hline Roorkee/summer solstice & 7 & 18.69 & -1.70 & 0.19 & 14.48 & 0.9 \\
\hline Roorkee/March equinox & 11 & 20.30 & -4.20 & 0.2 & 14.25 & 0.908 \\
\hline \multicolumn{7}{|l|}{ Perez } \\
\hline Roorkee/winter solstice & - & 20.89 & 7.65 & 0.19 & 12.87 & 0.97 \\
\hline Roorkee/summer solstice & - & 25.75 & -21.56 & 0.14 & 22.93 & 0.91 \\
\hline Roorkee/March equinox & - & 22.41 & -5.80 & 0.22 & 16.83 & 0.91 \\
\hline
\end{tabular}

Table 7. Error metrics for best fit CIE sky and Perez model predicted values for Delhi city

\begin{tabular}{|c|c|c|c|c|c|c|}
\hline City/season & $\begin{array}{c}\text { CIE } \\
\text { sky type }\end{array}$ & $\begin{array}{c}\text { RMSE } \\
(\%)\end{array}$ & $\begin{array}{l}\mathrm{MBE} \\
(\%)\end{array}$ & $\begin{array}{l}\text { Standard } \\
\text { deviation }\end{array}$ & $\begin{array}{c}\text { Percentage } \\
\text { error }\end{array}$ & $\begin{array}{l}\text { Correlation } \\
\text { coefficient }\end{array}$ \\
\hline \multicolumn{7}{|l|}{ CIE } \\
\hline Delhi $20^{\circ}$ solar altitude/winter & 10 & 24.48 & -6.45 & 0.24 & 16.67 & 0.8 \\
\hline Delhi $40^{\circ}$ solar altitude/winter & 11 & 27.46 & -3.89 & 0.25 & 18.87 & 0.85 \\
\hline \multicolumn{7}{|l|}{ Perez } \\
\hline Delhi $20^{\circ}$ solar altitude/winter & - & 29.41 & -1.67 & 0.29 & 20.27 & 0.77 \\
\hline Delhi $40^{\circ}$ solar altitude/winter & - & 26.95 & 2.10 & 0.25 & 18.63 & 0.84 \\
\hline
\end{tabular}

Here the $\bar{x}$ represents the measured values obtained from the iso-luminance contours and $x_{i}$ represents the predicted luminance values by the Perez and CIE sky model.

Apart from the above mentioned metrics, percentage error, standard deviation and coefficient of correlation were also computed between the predicted and measured values.

\section{Results and discussion}

The error metrics between the model predicted values and measured data for all three seasons of Roorkee is shown in Table 6. The measured sky luminance values at $10^{\circ}$ sky altitude for winter solstice were not considered in the comparative study as the inclusion resulted in an increase of $20 \%$ in the root mean square error value. The measurement at low sky altitude is prone to error as a large part of the path of light traverses through the atmosphere close to the earth. Due to the presence of suspended particles and moisture in the atmosphere close to the earth, scattering of the light rays occurs, which affects the luminance measurement at the stations and may lead to an erroneous measured luminance value. As can be seen from the table, the CIE model fits the sky luminance distribution better than the Perez model at 12 noon for Roorkee city in all the three seasons. The CIE model has the least error during the summer solstice season whereas the Perez model has the least error during the winter solstice season. The CIE sky type 11 was chosen as the sky type for the winter solstice and March equinox seasons and CIE sky type 7 for the summer solstice season for prediction using the CIE sky model. Mean bias error shows that both Perez and CIE sky model overestimate the relative luminance in the winter season and underestimate it in the other two seasons. The root mean square error and percentage error in the Perez model predicted values show an increase with the rise in solar altitude, whereas there is no specific pattern for the CIE model predicted values. Standard deviation is around 0.2 for CIE model predicted value while it varies from 0.14 to 0.22 for Perez model predicted values. Coefficient of correlation is above 0.9 for both the models.

The error metrics between model predicted values and measured data for Delhi at different solar altitudes are shown in Table 7. It can be seen from the table that the CIE model has a lower root mean square error at $20^{\circ}$ solar altitude but a slightly higher root mean square error at $40^{\circ}$ solar altitude compared to the Perez model predicted values. The error is higher at lower solar altitude for the Perez sky model whereas it is lower at lower solar altitude for the CIE sky model. The CIE sky type changes with the variation in solar altitude. The partly cloudy CIE skies of type 10 and 11 were found to be suitable sky types for prediction of sky luminance distribution at $20^{\circ}$ and $40^{\circ}$ solar altitudes respectively using the CIE sky 
RESEARCH ARTICLES

Table 8. Error metrics for best fit CIE sky and Perez model predicted values for Mumbai and Nagpur city

\begin{tabular}{lcccccc}
\hline City/season & $\begin{array}{c}\text { CIE } \\
\text { sky type }\end{array}$ & $\begin{array}{c}\text { RMSE } \\
(\%)\end{array}$ & $\begin{array}{c}\text { MBE } \\
(\%)\end{array}$ & $\begin{array}{c}\text { Standard } \\
\text { deviation }\end{array}$ & $\begin{array}{c}\text { Percentage } \\
\text { error }\end{array}$ & $\begin{array}{c}\text { Correlation } \\
\text { coefficient }\end{array}$ \\
\hline CIE & 10 & 14.60 & -5.60 & 0.2 & 11.34 & 0.95 \\
$\quad$ Mumbai/winter & 10 & 11.90 & -7.90 & 0.16 & 9.47 & 0.97 \\
$\quad$ Nagpur/winter & & & & & & \\
Perez & - & 19.63 & 1.50 & 0.13 & 12.53 & 0.93 \\
$\quad$ Mumbai/winter & - & 17.13 & -4.70 & 0.09 & 14.04 & 0.94 \\
$\quad$ Nagpur/winter & - & & & & & \\
\hline
\end{tabular}

model. Standard deviation is around 0.25 for CIE model whereas it goes up to 0.29 for the Perez model predicted values. Coefficient of correlation is around 0.8 for both the models with lower correlation coefficient of 0.77 at $20^{\circ}$ solar altitude in Delhi climate.

The relative luminance from the measured values for Nagpur and Mumbai city obtained from Narasimhan and Saxena's study ${ }^{2}$ were compared against the Perez and CIE model predicted values for the same locations. The results are shown in Table 8. CIE model predicts the sky luminance distribution better than the Perez model for both Mumbai and Nagpur city. The CIE sky type 10 was found to be the suitable sky type for both Mumbai and Nagpur region. CIE sky model underestimates the luminance values for Mumbai, whereas there is no specific pattern shown by the Perez sky model. The root mean square error for both CIE and Perez sky model falls below 30\% for all the cities and seasons. Standard deviation is lower in the Perez model predicted values, which is unlike the measured values for other two cities. Coefficient of correlation is higher for CIE model predicted values.

From the results of the comparison study, it can be concluded that the CIE sky model predicts sky luminance distribution better than the Perez sky model if one knows the correct sky type. Identification of the correct sky type requires measured luminance data which is not easily available in India. A wrong sky type may result in an error in predicted sky luminance values and lead to inefficient design. In the absence of any luminance data, the suitable CIE sky types identified in the present study can be used for prediction of sky luminance for places in the vicinity of the current cities and with similar climatic conditions. In the absence of sky luminance data and knowledge of the suitable CIE sky type, one can still resort to the Perez sky model as it still predicts the sky luminance distribution within reasonable accuracy.

As the CIE sky model is the current standard of sky luminance prediction and is used by many softwares for daylighting design, a methodology is needed to identify a suitable sky type for the daylighting design of windows in the location where measured luminance data are not available. The following section presents a framework to identify a suitable design CIE sky type for passive window design in such locations.

\section{Framework for identifying CIE design sky for various locations}

For the passive design of windows for daylighting, a low solar altitude sky luminance distribution is used. Choosing sky luminance distribution at low solar altitude ensures the presence of sufficient daylight throughout the working hours and hence is a suitable assumption for selection of design sky. Daylight illumination levels are quite low to be used for task illumination in the first hour after sunrise. After the first hour, sufficient daylight is available to be considered for utilization in task illumination inside the building; therefore $15^{\circ}$ solar altitude luminance distribution is considered for the design sky. As the sky luminance distribution also changes with weather conditions during the year, window design based on a sky type having minimum illumination among the twelve months will ensure sufficient daylight during the whole year. A CIE sky type satisfying the abovementioned conditions of a design sky needs to be identified for locations without measured luminance data. Perez sky model can be utilized for the purpose as explained in the following paragraph.

It can be seen from Tables 5 to 7 that the root mean square deviation of the CIE and Perez model predicted values from the measured values are close to each other and the difference between them is below $7 \%$. The root mean square deviation and mean bias deviation of the Perez and CIE model predicted values from the measured data are comparable and close to each other. It can be deduced from this observation that the Perez sky model predicts the sky luminance values less precisely than, but close to the CIE sky model. In the absence of measured sky luminance data, sky luminance distribution predicted by the Perez sky model can be used to identify a suitable design CIE sky type for the Indian Tropical region. The steps of the framework for identification of CIE skies are as follows: (i) Relative sky luminance is predicted at $15^{\circ}$ solar altitude through the Perez sky model using averaged monthly solar radiation of typical meteorological year data for all the 12 months in a year. (ii) The best-fit CIE sky type for each month is obtained by comparing the Perez sky model predicted values obtained in step 1 and $15 \mathrm{CIE}$ sky types using root mean square error metric. (iii) Global 


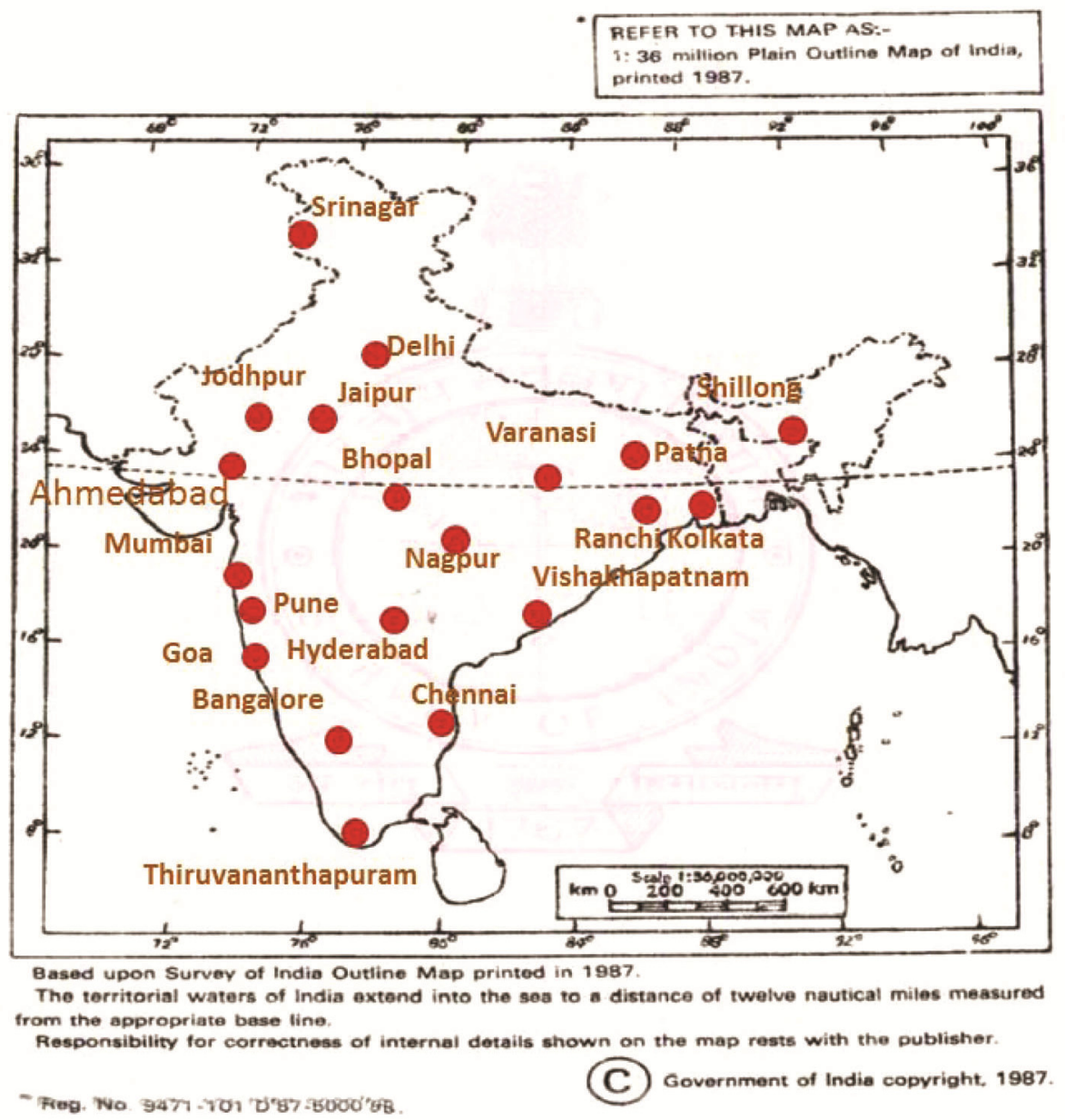

Figure 1. Map showing various locations chosen for the study ${ }^{25}$ (with permission).

horizontal illumination is calculated for each month using the best-fit CIE sky type luminance distribution obtained in step 2 for the respective months. (iv) Best-fit CIE sky types having the minimum, second minimum and third minimum global horizontal illumination for the location are selected. (v) CIE design sky is selected from among the three sky types obtained in step 4 based on the frequency of occurrence and climatic conditions.

Using the above procedure, the design CIE sky can be identified for any location where the measured luminance data is not available. The above-defined framework was applied to the Indian tropical conditions to identify CIE design skies for major climatic zones in India.

\section{Identification of design skies for Indian climate using the proposed framework}

Typical meteorological year data for 20 cities is available in the solar radiation handbook ${ }^{18}$; therefore CIE design skies are identified in these 20 cities. Among these 20 cities, 9 belonged to the composite climatic zone, 7 to warm-humid, 2 to cold and one each from hot-dry and temperate climatic zone. The locations selected for the study are shown in Figure 1. The radiation data for the typical meteorological year of all the cities were taken from the solar radiation handbook ${ }^{18}$.

After the identification of best fit CIE sky types using steps 1 and 2 of the framework, horizontal illumination is obtained from the absolute luminance values. CIE sky model gives the relative luminance of a sky element as a ratio of the zenith luminance. For obtaining absolute luminance and illumination on a plane from these relative luminance values, zenith luminance is required, either measured or modelled. Due to the lack of measured zenith luminance data at Indian stations, zenith luminance prediction models were employed for the study. The following section is about the readily available zenith luminance models and the procedure followed to select a suitable luminance model.

\section{Zenith luminance models}

Dogniaux $^{22}$ proposed an equation for the calculation of zenith luminance using Linke turbidity factor $(T)$ and 
solar altitude $\left(Z_{s}\right)$ at the time and location under consideration. The equation is as given below:

$$
\left.L_{z}=(1.234 T-0.252) \tan Z_{s}+0.112 T-0.0169\right) .
$$

Perez et al. ${ }^{23}$ in 1990 proposed another equation for modelling of zenith luminance from diffused horizontal irradiance and sky condition parameters as given below.

$$
L_{v z}=I_{\mathrm{DHI}}\left[f_{i}+g_{i} \cos Z_{s}+h_{i}^{\prime} \exp \left(-3 Z_{s}\right)+j_{i} \Delta\right],
$$

where $f_{i}, g_{i}, h_{i}^{\prime}$ and $j_{i}$ are the sky condition parameters which depend on the value of sky clearness and sky brightness factor. Sastri and Manmohan ${ }^{24}$ studied the equations proposed by various authors for their adequacy in predicting the variability of zenith luminance with solar altitudes in the tropical climatic zone of Delhi (India). In the study, zenith luminance was measured at different solar altitudes for winter and summer months in Delhi and the predicted values were checked against the measured values. They concluded that the Dogniaux formula gives the best possible representation of the variability of zenith luminance with solar altitude in tropical climates, if the precise value of the Linke turbidity factor is used. Perez zenith luminance model was not considered in the study. To identify which of the two models predict zenith luminance in a better way, Zenith luminance modelled through Dogniaux's equation and Perez's equation were compared with the measured values. Measured values at different solar altitudes were taken from Manmohan and Sastri's study ${ }^{24}$. Hourly values of the Linke turbidity factor were taken from the solar radiation handbook. A curve between percentage error of modelled values and solar altitude for the two equations for summer and winter season is shown in Figures 2 and 3 respectively. As it is clear from the curve that the percentage error is lower in the zenith luminance values predicted through Dogniaux's equation, it is therefore preferred over Perez's equation. The large error can be attributed to an error in the value of turbidity factor as the turbidity factor of the year of measurement may differ from typical meteorological year data. The error is large at low solar altitudes, while it decreases as the solar altitude increases. At low solar altitudes, the path of light traversing through the atmosphere close to the earth increases, which increases the scattering of light rays. Therefore, the effect of turbidity factor is more pronounced at low solar altitudes giving a large error value.

Absolute luminance values were obtained from the relative luminance using the modelled zenith luminance through the Dogniaux equation. The total illumination due to all of the sky elements was obtained from the following equation:

$$
E=\int_{0}^{\pi / 2} \int_{0}^{2 \pi} L v(\theta, \phi) \sin \theta \cos \theta \mathrm{d} \theta \mathrm{d} \phi,
$$

where $\phi$ varies from 0 to $2 \pi$ and $\theta$ varies from 0 to $\pi / 2$.
Here a closed-form solution cannot be obtained for the integration of the absolute luminance values; therefore numerical integration method was used for obtaining the illuminance. The $2 \mathrm{D}$ trapezoidal rule was employed in this study for obtaining the illuminance from the absolute luminance values.

\section{Identification of CIE skies}

Relative sky luminance distribution was predicted at $15^{\circ}$ solar altitude using the Perez sky model for the 20 locations in all 12 months. The best-fit CIE sky types corresponding to the Perez model predicted values at $15^{\circ}$ solar altitude were then identified through the root mean square error metric for twelve months of each location. Figure 4 shows the best-fit CIE skies at $15^{\circ}$ solar altitude identified for different locations in the form of a heat map. The sky conditions corresponding to each sky type can be

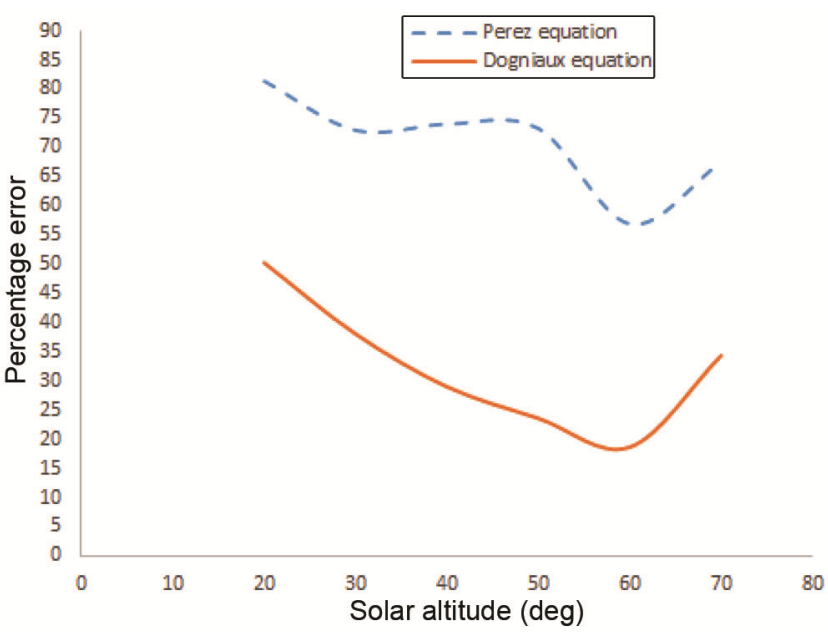

Figure 2. Variation of percentage error in predicted zenith luminance through Perez and Dogniaux equation at different solar altitudes in summer.

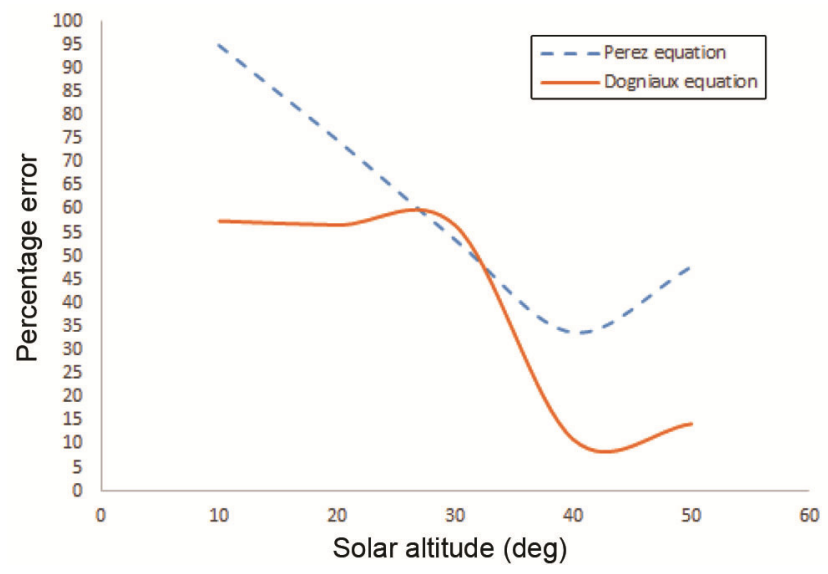

Figure 3. Variation of percentage error in predicted zenith luminance through Perez and Dogniaux equation at different solar altitudes in winter. 


\begin{tabular}{|c|c|c|c|c|c|c|c|c|c|c|c|c|}
\hline \multirow{2}{*}{ Location } & \multicolumn{12}{|c|}{ Best fit CIE sky during the month of } \\
\hline & Jan & Feb & Mar & Apr & May & Jun & Jul & Aug & Sep & Oct & Nov & Dec \\
\hline Srinagar & 3 & 12 & 12 & 12 & 14 & 14 & 15 & 3 & 12 & 12 & 12 & 12 \\
\hline Shillong & 12 & 11 & 11 & 11 & 12 & 11 & 11 & 11 & 8 & 11 & 12 & 12 \\
\hline Delhi & 11 & 10 & 10 & 11 & 10 & 11 & 12 & 11 & 11 & 11 & 11 & 11 \\
\hline Jaipur & 11 & 11 & 10 & 11 & 11 & 11 & 11 & 11 & 11 & 11 & 11 & 11 \\
\hline Patna & 12 & 11 & 11 & 11 & 11 & 11 & 12 & 11 & 12 & 11 & 11 & 12 \\
\hline Varanasi & 12 & 11 & 11 & 12 & 11 & 11 & 12 & 12 & 12 & 11 & 11 & 11 \\
\hline Ahmedabad & 12 & 11 & 11 & 11 & 11 & 11 & 12 & 12 & 8 & 10 & 11 & 11 \\
\hline Bhopal & 12 & 11 & 11 & 11 & 11 & 12 & 12 & 12 & 12 & 11 & 11 & 11 \\
\hline Ranchi & 11 & 11 & 11 & 11 & 12 & 12 & 12 & 12 & 12 & 10 & 11 & 10 \\
\hline Nagpur & 11 & 11 & 10 & 11 & 10 & 10 & 11 & 8 & 8 & 10 & 11 & 11 \\
\hline Hyderabad & 12 & 12 & 11 & 12 & 11 & 12 & 12 & 14 & 12 & 11 & 12 & 12 \\
\hline Jodhpur & 11 & 11 & 10 & 11 & 11 & 11 & 10 & 10 & 11 & 11 & 11 & 11 \\
\hline Bangalore & 11 & 12 & 12 & 12 & 12 & 12 & 12 & 12 & 11 & 12 & 11 & 12 \\
\hline Kolkata & 12 & 12 & 11 & 11 & 11 & 11 & 12 & 11 & 11 & 12 & 12 & 12 \\
\hline Mumbai & 11 & 10 & 10 & 12 & 10 & 14 & 3 & 3 & 11 & 11 & 12 & 11 \\
\hline Pune & 11 & 11 & 11 & 12 & 11 & 11 & 14 & 11 & 11 & 11 & 12 & 12 \\
\hline Vishakhapatnam & 10 & 10 & 11 & 11 & 10 & 12 & 11 & 11 & 11 & 12 & 12 & 11 \\
\hline Goa & 12 & 12 & 12 & 12 & 11 & 11 & 12 & 14 & 12 & 11 & 12 & 12 \\
\hline Chennai & 11 & 11 & 8 & 12 & 11 & 11 & 11 & 11 & 11 & 11 & 11 & 12 \\
\hline Thiruvanthapuram & 12 & 11 & 10 & 11 & 11 & 11 & 11 & 11 & 12 & 8 & 12 & 11 \\
\hline
\end{tabular}

Figure 4. Heat map for the best-fit CIE skies corresponding to the Perez model predicted values at $15^{\circ}$ solar altitude.

seen in Table 5. The yellow shaded boxes represent the partly cloudy and white blue sky. The green shaded boxes represent the clear skies of types 12 to 14 where the darker shade depicts more clearer sky. Red shaded boxes represent the overcast sky types. It can be seen from the heat map that the best-fit CIE skies identified for Indian cities mostly fall under the clear or partly cloudy sky category of types 10,11 or 12 with a rare occurrence of overcast sky conditions owing to extreme weather conditions. Sky type 11 (white-blue sky) has the highest frequency of occurrence among all the sky types. It can be inferred from the results that the Indian tropical conditions have predominantly clear sky or partly cloudy sky at low solar altitude.

Global horizontal illuminance for the corresponding month and solar altitude were calculated using absolute luminance values obtained through the best-fit CIE sky and Dogniaux zenith luminance model. Table 9 shows the global horizontal illumination calculated using the corresponding best-fit CIE sky for the twelve months at different locations. Table 7 gives the least three illumination values among the twelve months for each location and Table 7 shows the corresponding values for CIE skies.

The first two rows of Table 10 show the design sky identified for the locations under cold climatic conditions. In Srinagar, the overcast sky type 3 has the minimum and the second minimum illumination among all the months. However, from Figure 4 it can be seen that sky type 3 is the best-fit CIE sky for only 2 out of 12 months and therefore is not frequent so as to be chosen as the design sky. Therefore, CIE sky type 12 having third minimum illumination was chosen as the design sky for Srinagar. Similarly in Shillong, CIE sky type 8 has the minimum illumination among the twelve months, but it is the best-fit sky for only one out of 12 months. Due to its transient occurrence, CIE sky type 11 having the second minimum illumination was chosen as the design sky for Shillong. Both cities have different design skies owing to the difference in the microclimatic conditions despite being in the same climatic zone. CIE sky type 12 was chosen as the CIE design sky for locations located in the cold climatic zone of the Himalayan region and CIE sky type 11 for the cold climatic zone of the northeastern region.

Sky type 11 was found to be predominant as a design sky in the locations with composite climate as can be seen in Table 10. Out of the 27 design skies having minimum illumination among the 12 months, 16 sky types were of type 11 . So CIE sky type 11 was proposed as a design sky for locations falling under the composite climatic zone.

For the cities under the warm and humid climatic zone, CIE sky type 11 was having minimum illumination for 5 out of 7 cities. CIE sky type 11 also has a good frequency of occurrence among the best-fit CIE skies of warm and humid climatic zone. CIE sky type 11 was chosen as the CIE design sky for cities falling under the warm and humid climatic zone. 
RESEARCH ARTICLES

Table 9. Global horizontal illumination using CIE sky model and Dogniaux zenith luminance at $15^{\circ}$ solar altitude for 12 months at different locations

\begin{tabular}{|c|c|c|c|c|c|c|c|c|c|c|c|c|}
\hline \multirow[b]{2}{*}{ Location } & \multicolumn{12}{|c|}{ Global Horizontal illumination (lux) } \\
\hline & January & February & March & April & May & June & July & August & September & October & November & December \\
\hline Shillong & 8090 & 8437 & 8363 & 9751 & 11,187 & 8360 & 6971 & 8639 & 5364 & 8641 & 8090 & 8400 \\
\hline Delhi & 18,313 & 15,068 & 14,925 & 20,422 & 19,935 & 28,277 & 36,630 & 27,367 & 23,508 & 18,563 & 15,756 & 18,896 \\
\hline Jaipur & 14,187 & 15,004 & 14,804 & 19,671 & 23,946 & 29,221 & 34,750 & 32,395 & 21,535 & 16,646 & 17,299 & 15,034 \\
\hline Varanasi & 22,815 & 18,500 & 17,144 & 21,046 & 23,030 & 27,112 & 37,220 & 29,197 & 27,775 & 18,284 & 17,450 & 20,340 \\
\hline Ahmedabad & 11,811 & 10,673 & 10,586 & 12,808 & 13,916 & 14,748 & 23,891 & 18,316 & 8800 & 11,169 & 11,421 & 10,309 \\
\hline Bhopal & 16,461 & 14,147 & 13,087 & 16,073 & 19,084 & 31,453 & 37,002 & 43,424 & 27,357 & 19,313 & 16,034 & 15,269 \\
\hline Ranchi & 15,188 & 16,222 & 14,880 & 16,670 & 19,740 & 35,138 & 39,788 & 39,703 & 29,233 & 13,375 & 12,797 & 9692 \\
\hline Nagpur & 11,419 & 11,785 & 10,199 & 12,252 & 10,197 & 11,407 & 14,195 & 8799 & 8609 & 10,684 & 12,809 & 11,975 \\
\hline Hyderabad & 16,645 & 17,843 & 15,504 & 20,333 & 21,919 & 27,798 & 35,454 & 48,631 & 30,689 & 23,202 & 23,465 & 15,622 \\
\hline Jodhpur & 11,142 & 10,682 & 9230 & 12,252 & 14,750 & 11,415 & 14,556 & 17,950 & 13,087 & 13,088 & 11,698 & 11,142 \\
\hline Bangalore & 26,874 & 19,753 & 22,661 & 28,423 & 35,158 & 48,556 & 53,919 & 52,581 & 48,170 & 43,574 & 39,214 & 64,706 \\
\hline Mumbai & 14,754 & 13,196 & 13,107 & 18,318 & 13,346 & 19,224 & 6361 & 7338 & 14,754 & 15,310 & 16,460 & 13,642 \\
\hline Pune & 12,810 & 11,777 & 11,698 & 13,668 & 11,694 & 12,804 & 17,688 & 12,251 & 11,697 & 13,088 & 14,601 & 13,981 \\
\hline Vishakhapatnam & 12,380 & 11,728 & 13,365 & 15,864 & 13,830 & 18,004 & 17,528 & 11,696 & 14,198 & 14,290 & 14,910 & 13,087 \\
\hline Goa & 11,190 & 11,254 & 11,190 & 13,048 & 11,694 & 11,415 & 13,355 & 17,692 & 12,739 & 11,698 & 11,500 & 11,810 \\
\hline Chennai & 11,977 & 12,876 & 8801 & 13,358 & 13,916 & 11,136 & 6970 & 15,584 & 11,141 & 11,421 & 13,367 & 12,741 \\
\hline Thiruvanthapuram & 12,555 & 13,780 & 14,625 & 27,605 & 28,022 & 41,734 & 42,692 & 38,653 & 32,176 & 16,960 & 20,267 & 11,613 \\
\hline
\end{tabular}

Table 10. Possible design skies for different locations from minimum from estimated minimum illumination

\begin{tabular}{|c|c|c|c|c|c|c|}
\hline Location & Latitude & Longitude & $\begin{array}{c}\text { Climatic zone } \\
\text { NBC } 2005 \text { (ref. 6) }\end{array}$ & $\begin{array}{l}\text { CIE sky type having } \\
\text { minimum illumination }\end{array}$ & $\begin{array}{l}\text { CIE sky type having second } \\
\text { minimum illumination }\end{array}$ & $\begin{array}{l}\text { CIE sky type having } \\
\text { third minimum illumination }\end{array}$ \\
\hline Srinagar & 34.08 & 74.8 & Cold & 3 & 3 & 12 \\
\hline Shillong & 25.58 & 91.89 & Cold & 8 & 11 & 12 \\
\hline Delhi & 28.7 & 77.1 & Composite & 10 & 10 & 11 \\
\hline Jaipur & 26.91 & 75.79 & Composite & 11 & 10 & 11 \\
\hline Patna & 25.59 & 85.14 & Composite & 11 & 11 & 11 \\
\hline Varanasi & 25.32 & 82.97 & Composite & 11 & 11 & 11 \\
\hline Ahmedabad & 23.02 & 72.57 & Composite & 8 & 11 & 11 \\
\hline Bhopal & 23.26 & 77.41 & Composite & 11 & 11 & 11 \\
\hline Ranchi & 23.34 & 85.31 & Composite & 10 & 11 & 10 \\
\hline Nagpur & 21.15 & 79.09 & Composite & 8 & 8 & 10 \\
\hline Hyderabad & 17.39 & 78.49 & Composite & 11 & 12 & 12 \\
\hline Jodhpur & 26.24 & 73.02 & Hot and dry & 10 & 11 & 11 \\
\hline Bangalore & 12.97 & 77.59 & Temperate & 12 & 12 & 11 \\
\hline Mumbai & 19.08 & 72.88 & Warm humid & 3 & 3 & 10 \\
\hline Pune & 18.52 & 73.86 & Warm humid & 11 & 11 & 11 \\
\hline Vishakhapatnam & 17.69 & 83.22 & Warm humid & 11 & 10 & 10 \\
\hline Goa & 15.3 & 74.12 & Warm humid & 12 & 12 & 12 \\
\hline Chennai & 13.08 & 80.27 & Warm humid & 11 & 8 & 11 \\
\hline Thiruvanthapuram & 8.52 & 76.94 & Warm humid & 11 & 12 & 11 \\
\hline
\end{tabular}

Typical meteorological year data for only Jodhpur city was available for hot and dry climatic zone in the solar radiation handbook ${ }^{18}$. CIE sky type 10 was obtained as having minimum illumination among the best-fit skies of different months for Jodhpur. CIE sky type 10 also had a good frequency of occurrence among the best fit CIE sky for the 12 months. Therefore, CIE sky type 10 was chosen as the CIE design sky for the hot and dry climatic zone.
Similarly, typical meteorological year data for only Bangalore city was available for the temperate climatic zone. CIE sky type 12 was obtained as having the minimum illumination among the 12 months for the temperate climatic zone. Sky type 12 also had a good frequency of occurrence as it is the best-fit CIE sky for 9 out of the 12 months. Therefore, CIE sky type 12 was chosen as the design sky for the cities under the temperate climatic zone. 
Table 11. Proposed design skies for major climatic zones in India

\begin{tabular}{ll}
\hline Climatic zone & Proposed design sky \\
\hline Hot and dry & CIE Sky type 11 \\
Warm and humid & CIE Sky type 11 \\
Composite & CIE Sky type 11 \\
Cold Himalayan region/northeast region & CIE Sky type 12/11 \\
Temperate & CIE Sky type 12 \\
\hline
\end{tabular}

Table 11 shows the recommended design skies for the different climatic zones. As can be seen from the table, the design skies identified for major climatic zones of India are mostly clear sky types (CIE sky type 11 or 12). With the exception of cold Himalayan and temperate climate region, CIE sky type 11 is the most suitable CIE design sky for passive window design in the Indian tropical region. The design skies proposed in Table 11 can be used for the passive design of windows for any city in the Indian tropical climatic region by identifying the climatic zone and corresponding CIE design sky for the city.

\section{Conclusion}

The CIE model predicts the sky luminance better than the Perez model in the Indian tropical condition if one knows the correct CIE sky type. If the correct CIE sky type is unknown, one can still resort to the Perez sky model to obtain sky luminance values with lesser precision. A framework was proposed for the identification of CIE design skies for window design using irradiation data in the absence of measured luminance data. A set of CIE design skies are identified for the major climatic zones of India using the proposed framework. It was observed during the study that the sky occurrences at low solar altitudes in the Indian tropical climate are predominantly clear belonging to the range of CIE sky types 10 to 12 . CIE sky type 11 is the most suitable CIE design sky for passive window design in the Indian tropical climatic region with the exception of the locations falling under cold Himalayan and temperate climatic zone region. The recommended set of CIE design skies given in Table 11 can be used for the passive design of windows for the locations falling under the respective climatic zones.

1. Bureau of Indian Standards (BIS), Guide for daylighting of buildings, IS: 2440, Delhi, India.

2. Narashiman, V. and Saxena, B. K., Measurement of luminance distribution of clear blue sky in India. Indian J. Pure Appl. Phys., 1967, 5, 83-86.

3. Lam, K. P., Mahdawi, A., Ullah, M. B., Ng, E. and Pal, E., Comparative study of sky luminance models in the tropical context Proceedings, Building Simulation 1997, International Building Performance Simulation Association (eds Spilter, J. D. and Hensen, J. L. M.), CVUT-Czech Technical University, Prague, Czechoslovakia, 1997, vol. 1, pp. 339-345.

4. Janjai S., A satellite-based sky luminance model for the tropics. Int. J. Photoenergy, 2013, 2013, 260319.
5. Perez, R., Seals, R. and Michalsky, J., All-weather model for sky luminance distribution preliminary configuration and validation. Sol. Energy, 1993, 50(3), 235-245.

6. Darula, S. and Kittler, R., CIE general sky standard defining luminance distributions, Proc. Conf. eSim 2002. The Canadian conference on building energy simulation. Montreal, Canada, 2002.

7. Larson, W. G. and Shakespeare, R., Rendering with Radiance: The Art and Science of Lighting Visualization, Morgan Kaufmann Publishers, Inc. San Francisco, 1998.

8. Reinhart C. F., Daysim version 3.0, 2012; http://daysim.ning.com/

9. Velux Daylight Visualizer, 2010; https://www.velux.com/article/ 2016/daylight-visualizer

10. Tregenza P. R., Standard skies for maritime climates. Light. Res Technol., 1999, 31(3), 97-106.

11. Mukherjee, S., CIE standard general sky type identification for Delhi during winter and summer. J. Opt., 2014, 43(3), 245-256.

12. Mukherjee, S. and Roy, B., Correlating Indian measured sky luminance distribution and Indian design clear sky model with five CIE standard clear sky models. J. Opt., 2011, 40(4), 150-161.

13. Li, D. H. W., Lau, C. C. S. and Lam, J. C., Standard skies classification using common climatic parameters. J. Sol. Energy Eng., 2004, 126(3), 957.

14. Mettanant, V., Chaiwiwatworakul, P. and Chirarattanon, S., A model of Thai's sky luminance distribution based on reduced CIE standard sky T types. Renew. Energ., 2017, 103, 739-749.

15. Bureau of Indian Standards (BIS), National Building code of India, Second Revision, SP-7, Delhi, India, 2005.

16. Sastri, V. D. P. and Manmohan, S. B., A sky-scanning photometer for the luminance distribution of sky. Pure Appl. Geophys., 1975, 113(1), 375-387.

17. International Organization for Standardization (ISO), Spatial distribution of daylight-CIE standard general sky, ISO 15469, Geneva, Switzerland, 2004.

18. IMD (India Meteorological Department), Solar Radiant Solar Radiant Energy, Ministry of Earth sciences, India, 2018; https:// mnre.gov.in/file-manager/UserFiles/solar_radiant_energy_over_ India.pdf

19. Hall, I. J., Prairie R. R., Anderson, H. E. and Boes, E. C., Generation of a typical meteorological year. Proceedings of the 1978 Annual Meeting of American section of International Solar Energy Society, Denver, 1978, p. 669.

20. NREL (National Renewable Energy Laboratory), National solar radiation database, 2018; https://nsrdb.nrel.gov/

21. Fox, D. G., Judging air quality model performance. Bull. Am. Meteorol. Soc., 1981, 62(5), 599-609.

22. Dogniaux, R., Distribution des luminanceszenithales pour des conditions de cielscrein Report appended to Circular no. 15 1967/71-July 1971 to Committee E-32 of the CIE (in French), 1971.

23. Perez, R. Ineichen, P. Seals, R., Modeling daylight availability and irradiance components from direct and global irradiance. Solar Energy, 1990, 44(5), 271-289.

24. Sastri, V. D. P. and Manmohan, S. B., Zenith luminance and total horizontal illuminance of the tropical clear sky. Light. Res. Technol., 1990, 22(4), 197-200.

25. Survey of India, Political map of India: Seventh Edition, Survey of India, Department of Science and Technology, India, 2017; http://www.surveyofindia.gov.in/pages/display/235-political-mapof-india.

Received 17 January 2019; revised accepted 9 April 2020

doi: $10.18520 / \mathrm{cs} / \mathrm{v} 119 / \mathrm{i} 3 / 473-484$ 